\title{
Twin mesospheric bores observed over Brazilian equatorial region
}

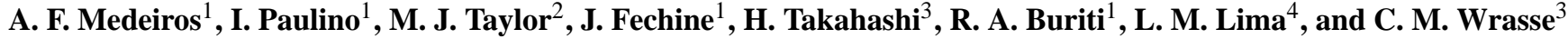 \\ ${ }^{1}$ Universidade Federal de Campina Grande, Campina Grande/PB, Brazil \\ ${ }^{2}$ Utah State University, Logan, UT 84322-4405, USA \\ ${ }^{3}$ Instituto Nacional de Pesquisas Espaciais, São José dos Campos/SP, Brazil \\ ${ }^{4}$ Universidade Estadual da Paraíba, Campina Grande/PB, Brazil
}

Correspondence to: I. Paulino (igopaulino@gmail.com)

Received: 26 August 2015 - Revised: 15 December 2015 - Accepted: 22 December 2015 - Published: 22 January 2016

\begin{abstract}
Two consecutive mesospheric bores were observed simultaneously by two all-sky cameras on 19 December 2006. The observations were carried out in the northeast of Brazil at two different stations: São João do Cariri $\left(36.5^{\circ} \mathrm{W}, 7.4^{\circ} \mathrm{S}\right)$ and Monteiro $\left(37.1^{\circ} \mathrm{W}, 7.9^{\circ} \mathrm{S}\right)$, which are by about $85 \mathrm{~km}$ apart. The mesospheric bores were observed within an interval of $\sim 3 \mathrm{~h}$ in the NIR OH and OI557.7 $\mathrm{nm}$ airglow emissions. Both bores propagated to the east and showed similar characteristics. However, the first one exhibited a dark leading front with several trailing waves behind and progressed into a brighter airglow region, while the second bore, observed in the $\mathrm{OH}$ layer, was comprised of several bright waves propagating into a darker airglow region. This is the first paper to report events like these, called twin mesospheric bores. The background of the atmosphere during the occurrence of these events was studied by considering the temperature profiles from the TIMED/SABER satellite and wind from a meteor radar.
\end{abstract}

Keywords. Atmospheric composition and structure (airglow and aurora) - meteorology and atmospheric dynamics (middle atmosphere dynamics; waves and tides)

\section{Introduction}

Since the discovery of mesospheric bores over the Hawaiian Islands in the beginning of 1990s (Taylor et al., 1995), prominent bore-like waves, which were initially termed mesospheric frontal events, have been observed and studied at equatorial and low latitudes (e.g., Medeiros et al., 2001, 2005; Fechine et al., 2005, 2009; Smith et al., 2005; Narayanan et al., 2012; Walterscheid et al., 2012), mid- latitudes (e.g., Smith et al., 2003; She et al., 2004; Yue et al., 2010; Smith, 2014) and high latitudes (e.g., Nielsen et al., 2006; Stockwell et al., 2006; Bageston et al., 2011a; Dalin et al., 2013).

These gravity waves are characterized by a leading front, usually followed by trains of waves, when observed in the nightglow emission. They can often appear in different emission, for instance, in the NIR OH and OI557.7 nm (OI5577) emission, in which their emission peaks are separated by about $10 \mathrm{~km}$ altitude (e.g., Medeiros et al., 2005).

Theories and observations had shown that mesospheric bores propagate for long distances trapped in ducts, which are regions between two evanescent levels and occur due to the thermodynamic condition of the local atmosphere. Depending on the position of the duct in the mesosphere and lower thermosphere (MLT), mesospheric bores can be observed with different contrast patterns in the airglow images (i.e., one can observe a dark bore in the higher airglow emission and bright in the lower airglow emission and vice versa). This was explained using the complementary effects (Dewan and Picard, 1998).

Dewan and Picard (2001) showed that these features are consistent with a ducted perturbation propagating horizontally at mesospheric heights. Subsequent lidar, imager and TIMED satellite measurements had demonstrated the existence of a temperature inversion layer supporting the ducted wave hypothesis (Smith et al., 2003, 2005; She et al., 2004; Fechine et al., 2009; Bageston et al., 2011a).

The wind as well as the temperature structures seems to have an important role in the formation and propagation of mesospheric bores into a duct. Doppler duct occurs when the wind is the most important process to the formation of it. Otherwise, if the temperature structure is predominant in the 
generation of the duct, it is termed a thermal duct. Moreover, ducts can arise to combine thermal and Doppler effects and are collectively termed dual ducts (Dewan and Picard, 2001).

In this paper, two consecutive mesospheric bores were observed in the airglow images within a time interval of $\sim 3 \mathrm{~h}$. These are termed "twin mesospheric bores". Coincident mesospheric wind profiles from the meteor radar and temperature profiles from the TIMED/SABER satellite were used in order to investigate the background propagation conditions for the bores.

\section{Instrumentation and observation}

From November 2005 to August 2008 coordinated airglow observations were made in the northeast of Brazil using all-sky imagers at two different stations: São João Cariri $\left(36.5^{\circ} \mathrm{W}, 7.4^{\circ} \mathrm{S}\right)$ and Monteiro $\left(37.1^{\circ} \mathrm{W}, 7.9^{\circ} \mathrm{S}\right)$, which are separated by a distance of about $85 \mathrm{~km}$.

Optical measurements at Monteiro used an all-sky imager system, which was described in detail by Taylor et al. (1995). This charge-coupled device (CCD) has an area of $6.45 \mathrm{~cm}^{2}$, high resolution, $1024 \times 1024$ backilluminated array with a pixel depth of 14 bits. Moreover, this equipment has a high quantum efficiency, low dark current $\left(0.5\right.$ electron pixel $\left.{ }^{-1} \mathrm{~s}^{-1}\right)$, low readout noise (15 electrons rms) and high linearity $(0.05 \%)$ that makes it possible to achieve quantitative measurements of airglow emissions. The camera uses a fast (f/4) all-sky telecentric lens system that enables high signal-to-noise $(20: 1)$ airglow images. Sequentially, images of near-infrared (NIR) OH and OI5577 were made using the exposed time of 15 and $90 \mathrm{~s}$, respectively. Measurements at São João Cariri were carried out using a similar optical device. The second imager was produced by KEO consultants, and the same time intervals of exposition for observing images of NIR OH and OI5577 were used.

Figure 1 shows the two mesospheric bores in the $\mathrm{OH}$ and OI5577 airglow images. The first one is (a) at 05:16 UT in the OI5577 layer and (c) at 05:25 UT in the OH layer. The second one is (b) at 07:00 in the OI5577 layer and (d) at 06:54 UT in the $\mathrm{OH}$ layer. The first bore presented a dark front in the airglow images of $\mathrm{OH}$ and OI5577. The second bore exhibited a bright front in the $\mathrm{OH}$ images. The contrast associated with the second bore was significantly low in the OI5577 images, but a dark leading front was recognized. These mesospheric bores were observed simultaneously at both observation sites in the airglow emissions. These bores were observed on 19 December 2006 and there was a time interval of $\sim 3 \mathrm{~h}$ between the first and second bores. These two bores exhibit similar properties and were all propagating eastward. However, the first event exhibited a dark leading front with several trailing waves behind and progressed into a brighter airglow region in both airglow emission, while the second bore was comprised of several bright waves propagating into a dark airglow region, as observed in the $\mathrm{OH}$ images. In the OI5577

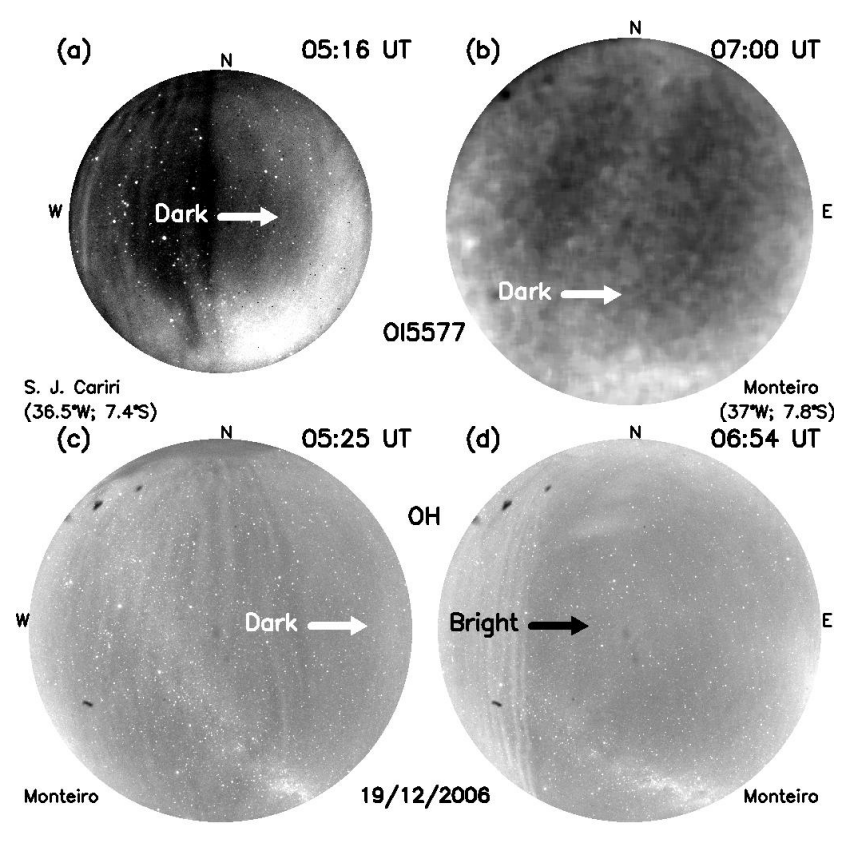

Figure 1. All-sky images of the twin mesospheric bores: (a) the first bore (front dark) observed at 05:25 UT in the $\mathrm{OH}$ image at Monteiro; (b) the second bore (front bright) observed at 06:54 UT in the $\mathrm{OH}$ image at Monteiro; (c) the first bore (front dark) observed at 05:16 UT in the OI5577 image at São João do Cariri; (d) the second bore (front dark) observed at 07:00 UT in the OI5577 image at Monteiro. Horizontal arrows indicate approximately the propagation direction of the bores. (See the movie in the Supplement for further details about the propagation of these bore, http://dx.doi.org/10.5446/17724.)

images, it was observed that a dark leading front progressed into a brighter airglow region. (See the movie in the Supplement for further details about the propagation of these bore, http://dx.doi.org/10.5446/17724.)

In the first case, the Dewan and Picard (1998) model predicts a duct below these airglow emission layers, and in the second case the duct would be between $\mathrm{OH}$ and OI5577 layers. Consequently, the ducting layer must be moved upward during the course of the night according to the prediction.

\section{Analysis and discussion}

Table 1 shows the parameters of the twin mesospheric bores. It should be noted that both bores have almost the same phase speed (observed and intrinsic) and almost same propagation direction. The wavelength and observed period are characteristics of their trailing waves. The intrinsic parameters were calculated using the background winds observed by the meteor radar deployed at São João do Cariri. These parameters were estimated using a 2-D fast Fourier transform spectrum analysis (Medeiros et al., 2003). The observed parameters of these bores compare favorably to the previous observations made in different places around the world (e.g., Medeiros 
Table 1. Horizontal parameters of the twin bores derived from the images and meteor radar measurements.

\begin{tabular}{|c|c|c|}
\hline & Bore 1 & Bore 2 \\
\hline Start (UT) & $03: 13$ & 06:03 \\
\hline End (UT) & $05: 31$ & - \\
\hline Propagation direction (degree from the north) & 97.3 & 104.4 \\
\hline Wavelength (km) & 17.0 & 33.2 \\
\hline Observed period $(\min )$ & 5.3 & 10.3 \\
\hline Observed phase speed $\left(\mathrm{m} \mathrm{s}^{-1}\right)$ & 53.0 & 53.7 \\
\hline Zonal wind at $87 \mathrm{~km}$ height $\left(\mathrm{m} \mathrm{s}^{-1}\right)$ & -11.4 & -7.4 \\
\hline Meridional wind at $87 \mathrm{~km}$ height $\left(\mathrm{m} \mathrm{s}^{-1}\right)$ & 49.3 & 24.4 \\
\hline Intrinsic period (min) & 4.0 & 8.2 \\
\hline Intrinsic phase speed $\left(\mathrm{m} \mathrm{s}^{-1}\right)$ & 70.7 & 66.9 \\
\hline
\end{tabular}

et al., 2001; Fechine et al., 2005; Bageston et al., 2011a, b; Narayanan et al., 2009; Smith, 2014)

An important factor used to characterize mesospheric bores is the presence of ducting condition. Some previous works have suggested that the occurrence of mesospheric bores could be related to the presence of thermal duct formed by a temperature inversion layer in the MLT (e.g., Smith et al., 2003, 2005; She et al., 2004; Bageston et al., 2011a). There are also reports on the thermal-Doppler ducts (e.g., Bageston et al., 2011b). To evaluate the occurrence of such structures in the night of these events (19 December 2006), temperature profiles obtained by the TIMED/SABER over São João do Cariri and Monteiro area were also analyzed.

Figure 2 shows the map of the observation sites. The dashed circle represents the field of view of the São João do Cariri (filled square) imager, and dotted circle shows the field of view of Monteiro (filled black circle). Six sets of soundings were made by the SABER instrument at geographical locations closer to the two all-sky imagers, and these soundings were made almost simultaneously to the second bore event (06:14 to 06:19 UT). Thus, the meteor radar and SABER measurements were combined in order to investigate in detail the nature of the second bore propagation condition in the MLT region.

Figure 3 shows the six temperature profiles from the SABER measurements. The symbol of each line is the same as the one used in Fig. 2 and is associated with its position on the map. The first temperature profile (line + triangle at 06:14 UT) shows an inversion layer with the peak at $\sim 81 \mathrm{~km}$ height. The last temperature profile (line + plus), therefore, shows a more pronounced peak at $\sim 90 \mathrm{~km}$ height. The temperature profiles observed at 06:16 (line + star) and 06:17 (line + asterisk) were within the field of view of the imager, which presented inversion layers with peaks around $87 \mathrm{~km}$ height.

Picard et al. (2004) found that, in the equatorial region, the daily mean radiance profiles for ascending and descending portions of the TIMED/SABER orbits differ by as much as $40 \%$ between an altitude of 70 and $110 \mathrm{~km}$, with the sign



Figure 2. Observation sites (filled square São João do Cariri; filled circle Monteiro) and the field of view of the imagers (dashed line circle São João do Cariri; dotted line circle Monteiro). Six soundings of the TIMED/SABER satellite are shown as well (triangle at 06:14 UT, diamond at 06:15, star at 06:16, asterisk at 06:17, big X at $06: 18$ and a plus at $06: 19$ ).

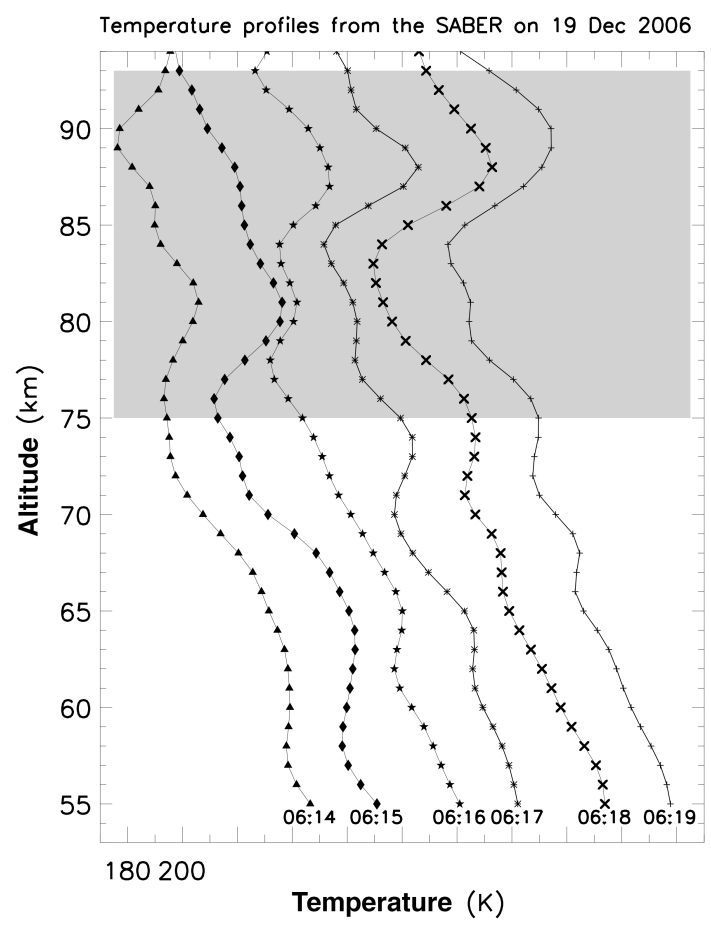

Figure 3. The six temperature profiles corresponding to the SABER soundings shown in Fig. 2. 


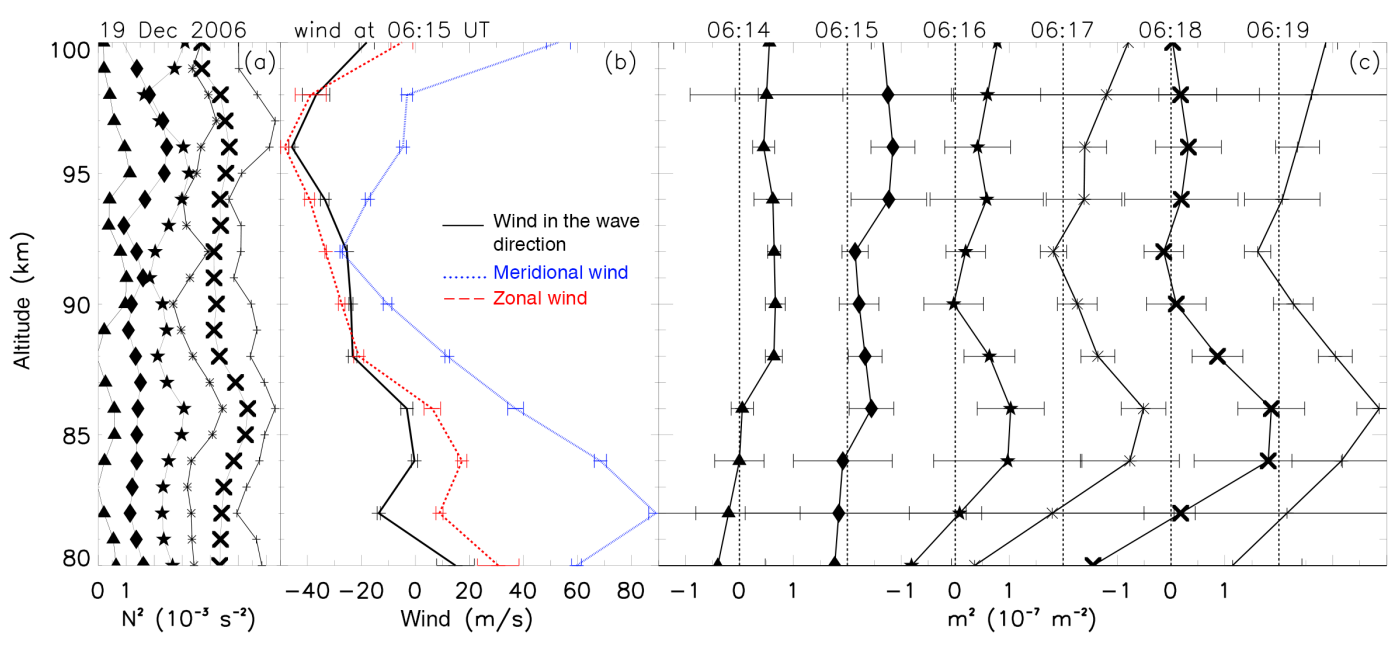

Figure 4. (a) Vertical profiles of the buoyancy frequency. (b) Meridional (dotted line), zonal (dashed line) and wind in the direction of the wave (solid line) at 06:15 obtained from the meteor radar. Error bars represent the uncertainties in the determination of the winds. (c) Square of the vertical wave number calculated using Taylor-Goldstein dispersion relation. Error bars represent the uncertainties in the estimation of the $m^{2}$ from the second differentiation of the wind.

changing in an oscillatory manner. The natural interpretation is that the $15 \mu \mathrm{m}$ emission rate directly reflects wave-like temperature and minor species density oscillations in the atmosphere. These, in turn, are basically manifestations of atmospheric tides, particularly the diurnal tide that dominates at low latitudes and produces the ascending/descending contrasts. Otherwise, the temperature oscillations arise from adiabatic tidal vertical displacements, which also modulate the atmospheric total density and the density of all minor constituents.

The present observations could suggest two possibilities: the inversion layer moved upwards or had a gradient in the latitude (i.e., it was lower in the low latitudes). Picard et al. (2004) also reported that the inversion layers are most often at around $\sim 83 \mathrm{~km}$ at night and $\sim 95 \mathrm{~km}$ at daytime.

Figure 4a shows the buoyancy frequency profiles derived from SABER temperature profiles. Figure $4 \mathrm{~b}$ shows the observed wind profiles at 06:15 UT derived from the meteor radar measurements. The blue dashed line represents the meridional (north-south) wind, the red dashed line is to the zonal (east-west) wind, and the black solid line represents the wind in the direction of the wave, which is quite similar to the zonal wind because the wave was propagating eastward.

The wave propagation condition can be verified from the square of the vertical wave number, $m^{2}$, given by the TaylorGoldstein relation:

$m^{2}=\frac{N^{2}}{(\bar{u}-c)^{2}}-\frac{\bar{u}_{z z}}{(\bar{u}-c)}-k_{\mathrm{H}}^{2}$,

where $\bar{u}$ is the background wind velocity in the direction of the wave propagation, $\bar{u}_{z z}$ is the second derivative of the wind with respect to the altitude in the propagation direction of the wave, $c$ is the phase speed of the wave, $k_{\mathrm{H}}=2 \pi / \lambda_{\mathrm{H}}$ is the horizontal wave number, $N^{2}$ is the buoyancy frequency, and $\lambda_{\mathrm{H}}$ is the horizontal wavelength.

The results for the $m^{2}$ using the six SABER soundings and the wind from the meteor radar are shown in Fig. 4c. If the $m^{2}$ is negative, it means that the wave does not have conditions to propagate vertically. Thus, a duct is formed whenever there is positive $m^{2}$ between two regions of negative $m^{2}$.

In Fig. 4c, duct region appears from 06:16 UT between 84 and $90 \mathrm{~km}$ height, and it is stronger in the other later profiles. It is important to keep in mind that the temperature profiles for 06:16 and 06:17 were within the field of view of the image (Fig. 2). This means that the duct, where the second bore propagated, was exactly in the $\mathrm{OH}$ layer. These SABER soundings were taken about $45 \mathrm{~min}$ earlier than the images shown in Fig. 1b. At this time (not shown here), no substantial differences between the leading front and the airglow environment could be observed, which suggest that the duct could be over the $\mathrm{OH}$ layer. A few minutes later, the leading front started to become brighter, as shown in Fig. 1b, indicating that the duct region must be moved up to a level higher than the $\mathrm{OH}$ layer but lower than the OI5577 layer.

If the right-side terms of the Eq. (1) were compared, one can see that the first term (due to the inversion layer) was much stronger than the other terms. It means that the inversion of the temperature in this region was caused by the thermal effects. Furthermore, this shape of the duct region was pronounced when the first and second terms of the Eq. (1) were considered (i.e., the gradient of the wind contributes favorably to the formation of this duct). 


\section{Summary}

Coordinated observations were made simultaneously in the northeast of Brazil using two all-sky CCD cameras, one located at São João do Cariri and the other at Monteiro, $\sim 85 \mathrm{~km}$ apart from each other. On the night of 18-19 December 2006, two consecutive bore events (twin mesospheric bores) were observed in the $\mathrm{OH}$ and OI5577 airglow emissions (the second one $\sim 3 \mathrm{~h}$ later than the first one). Both waves exhibited similar spectral characteristics and propagated eastward, but they exhibited different complementary patterns in the airglow images. Using supplementary measurements from the TIMED/SABER satellite and a meteor radar, the duct condition could be studied when the second bore started to be observed in the airglow images.

Based on the theory for the mesospheric bores and the observations of this work, the first bore probably propagated into a duct below the $\mathrm{OH}$ layer $(<87 \mathrm{~km}$ height) and the second bore occurred into a thermal duct that started overlapping to the $\mathrm{OH}$ layer and moved upward over time. However, at the end of the observation, the duct for the second bore was still below the OI5577 layer ( $<96 \mathrm{~km}$ height).

\section{Data availability}

If someone wants access to these data, please contact either A. F. Medeiros (afragoso@df.ufcg.edu.br) or H. Takahashi (hisao.takahashi@inpe.br).

\section{The Supplement related to this article is available online at doi:10.5194/angeo-34-91-2016-supplement.}

Acknowledgements. Support for these measurements was provided by NSF grant ATM 0000959 and NASA grant NNG04GA136 as part of coordinated measurements with the TIMED satellite. A. F Medeiros acknowledges the CAPES grant for providing financial support to visit USU during 2006-2007. This work has been also financed by the CNPq (no. 473473/2013-5, no. 301078/2013-0, no. 478117/2013-2).

The images and wind measurements used to produce the results of this paper were obtained from the Observatório de Luminescência Atmosférica da Paraíba at São João do Cariri, which is supported by the Universidade Federal de Campina Grande and Instituto Nacional de Pesquisas Espaciais.

The topical editor, C. Jacobi, thanks J. V. Bageston and P. R. Fagundes for help in evaluating this paper.

\section{References}

Bageston, J. V., Wrasse, C. M., Batista, P. P., Hibbins, R. E., C Fritts, D., Gobbi, D., and Andrioli, V. F.: Observation of a mesospheric front in a thermal-doppler duct over King George Island, Antarctica, Atmos. Chem. Phys., 11, 12137-12147, doi:10.5194/acp11-12137-2011, 2011a.

Bageston, J. V., Wrasse, C. M., Hibbins, R. E., Batista, P. P., Gobbi, D., Takahashi, H., Andrioli, V. F., Fechine, J., and Denardini, C. M.: Case study of a mesospheric wall event over Ferraz station, Antarctica ( $\left.62^{\circ} \mathrm{S}\right)$, Ann. Geophys., 29, 209-219, doi:10.5194/angeo-29-209-2011, $2011 \mathrm{~b}$.

Dalin, P., Connors, M., Schofield, I., Dubietis, A., Pertsev, N., Perminov, V., Zalcik, M., Zadorozhny, A., McEwan, T., McEachran, I., Grønne, J., Hansen, O., Andersen, H., Frandsen, S., Melnikov, D., Romejko, V., and Grigoryeva, I.: First common volume ground-based and space measurements of the mesospheric front in noctilucent clouds, Geophys. Res. Lett., 40, 6399-6404, doi:10.1002/2013GL058553, 2013.

Dewan, E. M. and Picard, R. H.: Mesospheric bores, J. Geophys. Res.-Atmos., 103, 6295-6305, doi:10.1029/97JD02498, 1998.

Dewan, E. M. and Picard, R. H.: On the origin of mesospheric bores, J. Geophys. Res.-Atmos., 106, 2921-2927, doi:10.1029/2000JD900697, 2001.

Fechine, J., Medeiros, A., Buriti, R., Takahashi, H., and Gobbi, D.: Mesospheric bore events in the equatorial middle atmosphere, J. Atmos. Sol.-Terr. Phy., 67, 1774-1778, doi:10.1016/j.jastp.2005.04.006, 2005.

Fechine, J., Wrasse, C. M., Takahashi, H., Medeiros, A. F., Batista, P. P., Clemesha, B. R., Lima, L. M., Fritts, D., Laughman, B., Taylor, M. J., Pautet, P. D., Mlynczak, M. G., and Russell, J. M.: First observation of an undular mesospheric bore in a Doppler duct, Ann. Geophys., 27, 1399-1406, doi:10.5194/angeo-271399-2009, 2009.

Medeiros, A., Taylor, M., Takahashi, H., Batista, P., and Gobbi, D.: An unusual airglow wave event observed at Cachoeira Paulista $23^{\circ}$ S, Adv. Space Res., 27, 1749-1754, doi:10.1016/S02731177(01)00317-9, 2001.

Medeiros, A., Fechine, J., Buriti, R., Takahashi, H., Wrasse, C., and Gobbi, D.: Response of $\mathrm{OH},\{\mathrm{O} 2\}$ and $\{\mathrm{OI} 5577\}$ airglow emissions to the mesospheric bore in the equatorial region of Brazil, Adv. Space Res., 35, 1971-1975, doi:10.1016/j.asr.2005.03.075, 2005.

Medeiros, A. F., Taylor, M. J., Takahashi, H., Batista, P. P., and Gobbi, D.: An investigation of gravity wave activity in the low-latitude upper mesosphere: Propagation direction and wind filtering, J. Geophys. Res.-Atmos., 108, 4411, doi:10.1029/2002JD002593, 2003.

Narayanan, V. L., Gurubaran, S., and Emperumal, K.: A case study of a mesospheric bore event observed with an all-sky airglow imager at Tirunelveli $\left(8.7^{\circ} \mathrm{N}\right)$, J. Geophys. Res.-Atmos., 114, D08114, doi:10.1029/2008JD010602, 2009.

Narayanan, V. L., Gurubaran, S., and Emperumal, K.: Nightglow imaging of different types of events, including a mesospheric bore observed on the night of February 15, 2007 from Tirunelveli $\left(8.7^{\circ} \mathrm{N}\right)$, J. Atmos. Sol.-Terr. Phys., 78-79, 70-83, doi:10.1016/j.jastp.2011.07.006, 2012.

Nielsen, K., Taylor, M. J., Stockwell, R. G., and Jarvis, M. J.: An unusual mesospheric bore event observed at high latitudes over Antarctica, Geophys. Res. Lett., 33, L07803, doi:10.1029/2005GL025649, 2006.

Picard, R. H., Wintersteiner, P. P., Winick, J. R., Mertens, C. J., Mlynczak, M. G., Russell III, J. M., Gordley, L. L., Ward, W. E., 
She, C. Y., and O'Neil, R. R.: Tidal and layer structure in the mesosphere and lower thermosphere from TIMED/SABER $\mathrm{CO}_{2}$ $15 \mu \mathrm{m}$ emission, in: Remote Sensing of Clouds and the Atmosphere IX, edited by: Schäfer, K. P., Comerón, A., Carleer, M. R., Picard, R. H., and Sifakis, N. I., Society of Photo-Optical Instrumentation Engineers (SPIE) Conference Series, 5571, 182-192, doi:10.1117/12.568060, 2004.

She, C. Y., Li, T., Williams, B. P., Yuan, T., and Picard, R. H.: Concurrent $\mathrm{OH}$ imager and sodium temperature/wind lidar observation of a mesopause region undular bore event over Fort Collins/Platteville, Colorado, J. Geophys. Res.-Atmos., 109, D22107, doi:10.1029/2004JD004742, 2004.

Smith, S., Friedman, J., Raizada, S., Tepley, C., Baumgardner, J., and Mendillo, M.: Evidence of mesospheric bore formation from a breaking gravity wave event: simultaneous imaging and lidar measurements, J. Atmos. Sol.-Terr. Phys., 67, 345-356, doi:10.1016/j.jastp.2004.11.008, 2005.

Smith, S. M.: The identification of mesospheric frontal gravitywave events at a mid-latitude site, Adv. Space Res., 54, 417-424, doi:10.1016/j.asr.2013.08.014, 2014.

Smith, S. M., Taylor, M. J., Swenson, G. R., She, C.-Y., Hocking, W., Baumgardner, J., and Mendillo, M.: A multidiagnostic investigation of the mesospheric bore phenomenon, J. Geophys. Res.-Space, 108, 1083, doi:10.1029/2002JA009500, 2003.
Stockwell, R. G., Taylor, M. J., Nielsen, K., and Jarvis, M. J.: A novel joint space-wavenumber analysis of an unusual Antarctic gravity wave event, Geophys. Res. Lett., 33, L08805, doi:10.1029/2005GL025660, 2006.

Taylor, M. J., Turnbull, D. N., and Lowe, R. P.: Spectrometric and imaging measurements of a spectacular gravity wave event observed during the ALOHA-93 Campaign, Geophys. Res. Lett., 22, 2849-2852, doi:10.1029/95GL02948, 1995.

Walterscheid, R. L., Hecht, J. H., Gelinas, L. J., Hickey, M. P., and Reid, I. M.: An intense traveling airglow front in the upper mesosphere-lower thermosphere with characteristics of a bore observed over Alice Springs, Australia, during a strong 2 day wave episode, J. Geophys. Res.-Atmos., 117, D22105, doi:10.1029/2012JD017847, 2012.

Yue, J., She, C.-Y., Nakamura, T., Harrell, S., and Yuan, T.: Mesospheric bore formation from large-scale gravity wave perturbations observed by collocated all-sky $\{\mathrm{OH}\}$ imager and sodium lidar, J. Atmos. Sol.-Terr. Phys., 72, 7-18, doi:10.1016/j.jastp.2009.10.002, 2010. 